\title{
An Atomic Beam Source for Actinide Elements: Concept and Realization
}

\author{
By B. Eichler* \\ Labor für Radio- und Umweltchemie, Paul Scherrer Institut, CH-5232 Villigen PSI, Switzerland
}

\section{S. Hübener}

Institut für Radiochemie, Forschungszentrum Rossendorf e.V., D-01314 Dresden, Germany

\author{
N. Erdmann, K. Eberhardt, H. Funk, G. Herrmann, S. Köhler, N. Trautmann \\ Institut für Kernchemie, Universität Mainz, D-55099 Mainz, Germany
}

G. Passler and F.-J. Urban

Institut für Physik, Universität Mainz, D-55099 Mainz, Germany

(Received April 3, 1997; accepted July 2, 1997)

\begin{abstract}
Atomic beams / Actinide elements / Resonance ionization mass spectroscopy / Volatilization
\end{abstract}

\begin{abstract}
Summary
For ultratrace analysis of actinide elements and studies of their atomic properties with resonance ionization mass spectroscopy (RIMS), efficient and stable sources of actinide atomic beams are required. The thermodynamics and kinetics of the evaporation of actinide elements and oxides from a variety of metals were considered, including diffusion, desorption, and associative desorption. On this basis various sandwich-type filaments were studied. The most promising system was found to consist of tantalum as the backing material, an electrolytically deposited actinide hydroxide as the source of the element, and a titanium covering layer for its reduction to the metal. Such sandwich sources were experimentally proven to be well suited for the production of atomic beams of plutonium, curium, berkelium and californium at relatively low operating temperatures and with high and reproducible yields.
\end{abstract}

\section{Introduction}

The volatility of actinide metals is frequently used in radio- and nuclear chemistry. To mention only a few applications: By evaporation-deposition of actinide metals on substrates [1], counting samples for $\alpha$ particles and spontaneous-fission fragments with high energy resolution are prepared as well as thin actinide targets for nuclear reaction studies. Gas chromatography of actinide metals in metal columns [2-4] revealed the separation of individual actinides on analytical and preparative scales, and provided with trace amounts insights into the adsorption of actinides on metallic surfaces and the respective binary systems [5, 6]. In resonance ionization mass spectroscopy (RIMS), atomic beams of actinide elements produced by volatilization are crossed with laser beams of different

\footnotetext{
* Author for correspondence.
}

colours for stepwise excitation and final ionization of the atoms. The ions are identified and counted in a time-of-flight mass spectrometer. RIMS is applied to determine actinide elements in up to now inaccessible small quantities, but is also used for the determination of basic atomic properties of actinide elements such as ionization potentials.

In our earlier work on trace element analysis $[7,8]$ and ionization potential measurements [9] with RIMS, atomic beams of neptunium and plutonium were produced from actinide oxides deposited on rhenium filaments and covered with thin rhenium or platinum-lead coatings. These "sandwich" sources had to be operated at high temperatures, around $2000 \mathrm{~K}$, and the beam yields varied from filament to filament by nearly two orders of magnitude [10], mainly due to imperfections and instabilities of the coatings. In order to develop more reliable atomic beam sources, thermodynamic and kinetic properties of the actinide elements and possible source materials were examined, as presented in sections 2 to 4 of this paper. Additional pertinent data, also for homologous lanthanides, are compiled elsewhere [11]. The result of these considerations is a tantalum-actinide oxide-titanium sandwich-type source whose superior properties for RIMS measurements are presented in section 5 .

\section{General requirements}

An atomic beam source for RIMS should deliver over a long period nearly constant particle fluxes, and should finally lead to an evaporation of a large fraction of the actinide element even in trace quantities when interactions with the backing and other source materials may interfere. The operation temperature of the sources should be as low as possible, to improve their overall thermal stability and to suppress background events due to thermal ionization. The same type of 
source should generally be applicable within the whole series of actinide elements.

The parameters which govern mass transfer and chemical state of the emitted particles depend basically on the material combination present in a particle-cave or particle-filament arrangement. For each combination, the kinetics of mass transfer and the thermochemistry of elementary processes have to be considered. On this basis the construction materials for the source and its operation conditions can be chosen.

\subsection{Mass transfer}

The elementary processes of mass transfer from a solid into a gas comprise evaporation, desorption and diffusion. In the following, we estimate the most important parameters which have to be met in an atomic beam source for actinide elements.

\subsubsection{Evaporation kinetics}

According to Langmuir's relation

$$
\mathrm{d} m / \mathrm{d} t=4.37 \cdot 10^{-5} \cdot p \cdot(M / T)^{1 / 2}
$$

the evaporation rate $\mathrm{d} m / \mathrm{d} t\left[\mathrm{~g} / \mathrm{cm}^{2} \mathrm{~s}\right]$ of a pure substance into vacuum is a function of the molar or atomic weight $M$, the vapour pressure $p$ [Torr], and the temperature $T[\mathrm{~K}]$. The relation gives an estimate of the volatility $(p)$ required to evaporate a given mass at a given temperature and time. For example [11], to evaporate $0.1 \mu \mathrm{g}$ of a substance with $M=244$ at $2000 \mathrm{~K}$ within $1200 \mathrm{~s}$ from an area of $1 \mathrm{~cm}^{2}$, the vapour pressure has to exceed $1 \cdot 10^{-8}$ bar, and $1 \cdot 10^{-5}$ bar for $100 \mu \mathrm{g}$. This applies to the saturation pressure over the pure substance or to the decomposition pressure over a decomposing solid.

\subsubsection{Desorption kinetics}

For quantities smaller than a monolayer covering, the volatility is determined by interactions between the evaporating species and the substrate material. With some simplifications [12], the time $t_{50 \%}$ required for $50 \%$ volatilization can be estimated from the activation enthalpy for desorption, $\Delta H_{\text {des }}[\mathrm{kJ} / \mathrm{mol}]$, and the temperature $T_{50 \%}[\mathrm{~K}]$ :

$$
\Delta H_{\text {des }}=2.303 \cdot R \cdot T_{50 \%} \cdot \log \left(t_{50 \%} \cdot v_{0} / 0.693\right)
$$

where $v_{0}$ is the basic vibration frequency of the adsorbed atom, typically $10^{12}$ to $10^{13} \mathrm{~s}^{-1}$, and $R$ the gas constant. In order to evaporate $50 \%$ of a substance at $2000 \mathrm{~K}$ within $1200 \mathrm{~s}, \Delta H_{\text {des }}$ should not exceed $600 \mathrm{~kJ} / \mathrm{mol}$; at $1000 \mathrm{~K}$ the limit is $300 \mathrm{~kJ} / \mathrm{mol}$ [11].

\subsubsection{Diffusion rate}

The actinide element can be applied as a deposit on a metal foil, as an implant into a foil or as a deposit covered with a coating. In the latter two cases, dif- fusion through the foil or coating plays a role. For diffusion controlled thermal release from a foil, the following relation [13] holds for large release rate $F$, independent of the initial distribution:

$$
F=1-\left(8 / \pi^{2}\right) \cdot \exp \left(D \cdot t / d^{2}\right) .
$$

To release $80 \%$ of a substance within $t=1200 \mathrm{~s}$ from a foil or through a coating of thickness $d=1 \mu \mathrm{m}$, a diffusion coefficient $D>10^{-12} \mathrm{~cm}^{2} / \mathrm{s}$ is needed. With

$$
D=D^{0} \cdot \exp (-Q / k \cdot T)
$$

operation temperatures $T$ can be estimated from the matrix-dependent constant $D^{0}$ and the activation energy of diffusion $Q$, with $k$ being the Boltzmann constant.

\subsection{Chemical identity}

The yield of actinide atomic beams can be reduced by competitive reactions. Surface ionization leads to desorption in ionic rather than atomic form. The relative number of ions to neutral atoms, $n_{i} / n_{0}$, depends on the difference between the electron work function $\Phi$ $[\mathrm{eV}]$ of the substrate and the first ionization potential $I_{i}[\mathrm{eV}]$ of the evaporated element, and on the temperature $T[\mathrm{~K}]$ according to the Langmuir equation:

$$
\frac{n_{i}}{n_{0}}=\frac{g_{i}}{g_{0}} \cdot \exp \left(\frac{\Phi-I_{i}}{k \cdot T}\right)
$$

where $g_{i}$ and $g_{0}$ are the statistical weights of the ground states of ion and atom, respectively. In order to minimize surface ionization, materials with low electron work function $\left(\Phi<I_{i}\right)$ have to be used, and the operation temperature has to be kept as low as possible.

Another interfering effect is molecular desorption which can occur from thermodynamic reasons, e.g., if the reducing power of the matrix metal for actinide monoxides is not sufficient to prevent their volatilization. Such an associative desorption may be due to contaminants present on the substrate surface or in the residual gas. Also, desorption as a dimeric [14] or intermetallic molecule [15] seems to be possible.

\section{Specific requirements for actinide elements}

In this section, relevant material properties of the actinide elements and their interaction with potential source materials will be discussed.

\subsection{Thermal volatilization of actinide metals and oxides}

Actinide sources are conveniently prepared by electrolytic deposition leading to hydroxides or by electroplating of nitrates. After subsequent heating, oxides are obtained. Hence, the behaviour of oxides is of primary interest in this context. 


\subsubsection{Dioxides and sesquioxides}

Dioxides and sesquioxides of the actinide elements are less suited for evaporation because of their extremely low vapour pressure. Also, the decomposition pressure of the oxides is low [11] even at high temperatures, as is known for substoichiometric dioxides of $\mathrm{Pa}$ [16], $\mathrm{Pu}$ [17], and Am [18], and for $\mathrm{Cm}_{2} \mathrm{O}_{3}$ [19]. Evaporation of actinide oxides is not a simple process [20]. Extensive high-temperature studies were reported for the dioxides of $\mathrm{Th}[21,22], \mathrm{Pa}[16], \mathrm{U}$ [23], $\mathrm{Np}$ [24], and $\mathrm{Pu}[17,18]$, and for the sesquioxides of Pu [25], Am $[20,21], \mathrm{Cm}[19,26], \mathrm{Bk}[20], \mathrm{Cf}[20,27]$, and Es [20]. Elementary actinides An, the monoxides AnO, and for $\mathrm{UO}_{2}$ and $\mathrm{PaO}_{2}$ also $\mathrm{AnO}_{2}$, were observed in the gas phase. For sesquioxides, $\mathrm{AnO}$ is the dominant species in the gas phase. Hence, the basic thermal dissociation reactions are most likely

$$
\mathrm{An}_{2} \mathrm{O}_{3} \leftrightarrow 2 \mathrm{AnO}(\mathrm{g})+\mathrm{O}(\mathrm{g})
$$

and

$$
\mathrm{An}_{2} \mathrm{O}_{3} \leftrightarrow 2 \mathrm{An}(\mathrm{g})+3 \mathrm{O}(\mathrm{g}) .
$$

The stability of monoxides in the gas phase is, thus, determining the dissociative evaporation of sesquioxides. In analogy to the behaviour of lanthanides [20] we expect, that at dissociation enthalpies of the monoxide $<700 \mathrm{~kJ} / \mathrm{mol}$, the species $\mathrm{AnO}(\mathrm{g})$ is preferentially formed; below $600 \mathrm{~kJ} / \mathrm{mol} \mathrm{AnO}(\mathrm{g})$ and $\mathrm{An}(\mathrm{g})$ appear simultaneously, and below $500 \mathrm{~kJ} / \mathrm{mol} A n(\mathrm{~g})$ is dominating. Hence, the major species in the evaporation of sesquioxides should be [20]: $\mathrm{PuO}, \mathrm{Am}, \mathrm{CmO}$, $\mathrm{BkO}+\mathrm{Bk}, \mathrm{Cf}$, and Es. It should be noted, that most studies of dissociative evaporation were carried out with metallic effusion cells where an influence of the wall material such as Ta, W, Mo, Re cannot easily be corrected for; an exception is Ref. [20] where a $\mathrm{ThO}_{2}$ cell was used.

\subsubsection{Monoxides}

The monoxides $\mathrm{AnO}(\mathrm{g})$ play a crucial role as intermediates in the thermal decomposition of higher oxides and as intermediates and equilibrium components in the reduction of actinide oxides by metals. In the older literature, the suboxides of $\mathrm{U}, \mathrm{Th}$, and $\mathrm{Pu}$ were considered to be refractory with high sublimation enthalpies $[21,25,28]$, but in more recent studies it is pointed out $[20,29,30]$ that pure monoxide phases were not prepared and the thermodynamic constants are uncertain.

The monoxides of $\mathrm{Th}, \mathrm{U}$, and $\mathrm{Pu}$ strongly tend to disproportionation at high temperatures [21], and the reactions of $\mathrm{Am}$ and $\mathrm{Cf}$ sesquioxides according to

$$
\mathrm{An}_{2} \mathrm{O}_{3}(\mathrm{~s})+\mathrm{An}(\mathrm{s}) \leftrightarrow 3 \mathrm{AnO}(\mathrm{s})
$$

have still large positive standard potentials $\Delta G$, $+429 \mathrm{~kJ} / \mathrm{mol}$ for Am and $+250 \mathrm{~kJ} / \mathrm{mol}$ for Cf. Presumably, stable solid monoxides can be formed only for mendelevium and nobelium.

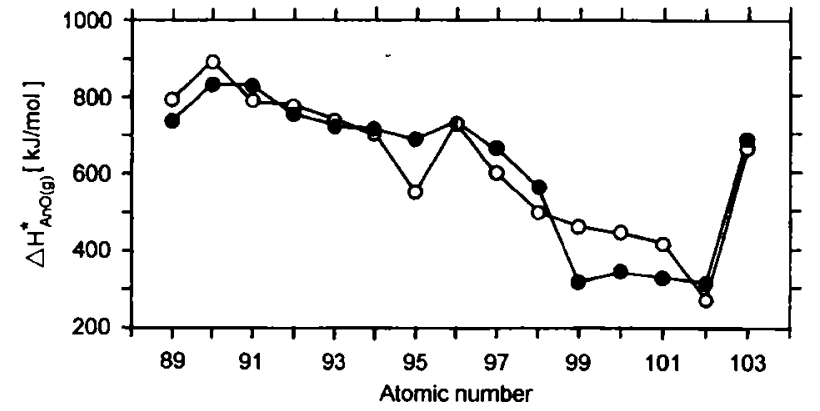

Fig. 1. Dissociation enthalpies of gaseous actinide monoxides: experimental and calculated values; dots from [29], circles from [20].

A higher stability is known for the gaseous monoxides formed in high-temperature reactions. On the basis of literature data, empirical relations were derived [29] between $\Delta H_{\mathrm{MeO}(\mathrm{g})}^{*}$, the formation enthalpies of gaseous monoxides from the gaseous monoatomic elements, and the standard sublimation enthalpies of the metals, $\Delta H_{\text {sub-Me }}$. For the divalent lanthanides, actinides and alkaline earths one obtains:

$$
-\Delta H_{\text {MeO(g) }}^{*}=-3.7811 \Delta H_{\text {subl-Me }}+179.6[\mathrm{~kJ} / \mathrm{mol}]
$$

and for all other lanthanides and actinides:

$$
-\Delta H_{\mathrm{MeO}(\mathrm{g})}^{*}=-0.5769 \Delta H_{\text {subl-Me }}-485.5[\mathrm{~kJ} / \mathrm{mol}] \text {. }
$$

These relations were used to estimate $\Delta H_{\text {Ano(g) }}^{*}$ when experimental actinide data were not available. The results [29] shown in Fig. 1 are in good agreement with a recent compilation [20] of experimental and estimated data. Both sets of data indicate that high-temperature vaporization of oxides and their thermal dissociation is not a practical approach for the production of actinide atomic beams, though in the evaporation of the heavier actinides, atomic species dominate. The limitation lies in the high temperatures required.

\subsubsection{Metals}

The vapour pressure data for the actinide metals $\mathrm{Pu}$, Am, Cm, Cf, Es [31], and Fm [32] show straight lines in a $\log p$ versus $1 / T$ presentation. The position of other actinides can reasonably well be estimated [11]. Clearly, the divalent metals, Cf, Es, Fm, Md, and No are most volatile. The trivalent metals $\mathrm{Am}, \mathrm{Cm}, \mathrm{Bk}$, and $\mathrm{Lr}$ show medium volatility. The polyvalent actinides are least volatile, with increasing volatility in the order Th, $(\mathrm{Pa}), \mathrm{U}, \mathrm{Np}$, and $\mathrm{Pu}$. All actinide metals fulfill the criterion of a minimum partial pressure postulated above, except thorium which is a limiting case but its volatilization could be achieved at temperatures above $2000 \mathrm{~K}$.

\subsection{Properties of source materials}

On the basis of the given stabilities and volatilities of actinide metals and oxides we have to consider the 


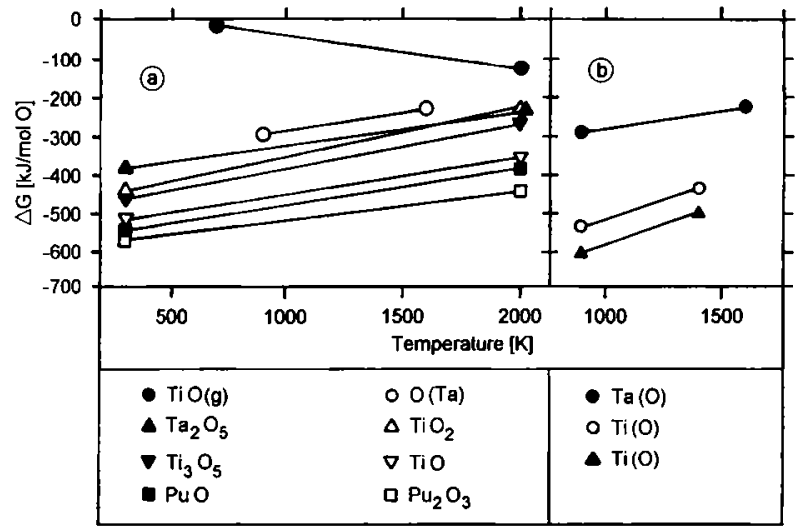

Fig. 2. (a) Thermodynamic standard potential $\Delta G$ (a) for oxides of titanium, tantalum, and plutonium [28] and (b) for solutions of oxygen in titanium [41] and tantalum [38] as a function of temperature. In (b), two lines are given for the Ti(O) system, experimentally obtained in contact with $\mathrm{MgO} / \mathrm{Mg}$ (circles) and $\mathrm{CaO} / \mathrm{Ca}$ (triangles) [41].

reductive, adsorptive, alloying, and diffusive properties of possible source materials to find combinations which yield efficient atomic beam sources. With regard to the reductive potential, the group IV and V metals are most interesting; thus, the following discussion will be focused on titanium and tantalum.

\subsubsection{Reductive potential}

Thermodynamic sinks for oxygen

Titanium and tantalum metal are strong reducing agents. The solubility of oxygen in titanium, zirconium and hafnium is remarkably high, whereas it is less pronounced in vanadium, niobium, and tantalum. From niobium and tantalum, oxygen can be released at high temperatures in vacuum, but not from titanium, zirconium and hafnium [33]. Even with the strongest reducing agents such as calcium, there remains a residual oxygen content of $0.07 \%$ in titanium [34]. Over $\mathrm{TiO}_{\mathrm{x}}$ containing $10 \%$ oxygen, the oxygen partial pressure is as low as $10^{-35} \mathrm{~Pa}$ at $1150 \mathrm{~K}$ [34]. In $\alpha$ titanium, oxygen can be dissolved up to 34 atom percent [35]. In $\beta$-titanium the solubility is lower, limited to 4 atom percent at $1473 \mathrm{~K}$. Thermochemical data for solutions of oxygen in the titanium phases are known $[36,37]$.

In tantalum, oxygen occupies the octaeder vacancies in an interstitial solid solution. The maximum solubility $c_{\max }$ in the monophase is [38]:

$$
\log c_{\max }[\text { atom \%] }=1.22-980 / T[\mathrm{~K}] \text {. }
$$

At high temperatures only $\mathrm{Ta}_{2} \mathrm{O}_{5}$ and oxygen-saturated metal coexist [39]. The solution enthalpy is -385 $\pm 9 \mathrm{~kJ} / \mathrm{mol} \mathrm{O}$ in the homogeneous phase region, and $-403 \pm 4 \mathrm{~kJ} / \mathrm{mol} \mathrm{O}$ in the two-phase region [40]. The thermodynamic standard potential $\Delta G_{\mathrm{L}}$ of a solution of oxygen in tantalum at infinite dilution is given by:

$$
\Delta G_{\mathrm{L}}[\mathrm{kJ} / \mathrm{mol} \mathrm{O}]=-382.745+0.0958 \cdot T[\mathrm{~K}] \text {. }
$$

Table 1. Differential molar enthalpies of adsorption $\Delta H_{\text {ads }}$, solution $\Delta H_{\mathrm{sL}}$, and segregation $\Delta H_{\mathrm{sE}}$, for interactions of oxygen with titanium and tantalum metal

\begin{tabular}{lccc}
\hline Metal & $\begin{array}{c}-\Delta H_{\text {ads }} \\
(\mathrm{kJ} / \mathrm{mol} \mathrm{O})\end{array}$ & $\begin{array}{c}-\Delta H_{\mathrm{SL}} \\
(\mathrm{kJ} / \mathrm{mol} \mathrm{O})\end{array}$ & $\begin{array}{c}-\Delta H_{\mathrm{SE}} \\
(\mathrm{kJ} / \mathrm{mol} \mathrm{O})\end{array}$ \\
\hline Titanium & 742 & 626 & 116 \\
Tantalum & 692 & 385 & 307 \\
\hline
\end{tabular}

Fig. 2a shows the thermodynamic standard potentials of the oxides of titanium, tantalum, and plutonium as a function of temperature [28]. It follows that the reduction of $\mathrm{Pu}_{2} \mathrm{O}_{3}$ to $\mathrm{Pu}$ by formation of pure singlephase oxides $\mathrm{TiO}_{2}$ and $\mathrm{Ta}_{2} \mathrm{O}_{5}$ is not favoured thermodynamically. However, the decrease of the $\Delta G$-values with decreasing oxygen content $\left(\mathrm{TiO}_{2} \rightarrow \mathrm{Ti}_{2} \mathrm{O}_{3} \rightarrow\right.$ $\mathrm{TiO}$ ) indicates an increase of the reductive potential which continues into the monophase region of the oxygen-metal solution. According to Fig. $2 b$ depicting the thermodynamic standard potentials for solutions of oxygen in metallic titanium and tantalum [38, 41], a reduction of $\mathrm{Pu}_{2} \mathrm{O}_{3}$ by formation of an oxygen solution of low concentration in the metals seems to be possible.

A thermodynamic sink for oxygen could also be its binding to metallic surfaces. In Table 1 thermochemical data are compiled [29] which characterize the distribution of oxygen between bulk phase and surface. One sees that the adsorptive binding characterized by $\Delta H_{\text {ads }}$ exceeds the solution enthalpy $\Delta H_{\mathrm{sL}}$, so that the reductive potential increases. However, this potential is only available for surface coverages less than a monolayer. The difference between the differential molar enthalpies $\Delta H_{\text {ads }}$ and $\Delta H_{\mathrm{SL}}$ gives the differential molar segregation energy for oxygen $\Delta H_{\mathrm{SE}}$. It is proportional to the driving force for an enrichment of oxygen at the surface under thermal stress of the solid solution. Table 1 also indicates that titanium is a stronger reducing agent than tantalum, and that oxygen is more easily enriched at the surface in tantalum than in titanium.

Reduction reactions of actinide oxides $\mathrm{AnO}_{x}$ with metals Me should proceed through the following steps:

$$
\begin{aligned}
& 2 \mathrm{AnO}_{2}+\mathrm{Me} \leftrightarrow \mathrm{An}_{2} \mathrm{O}_{3}+\mathrm{Me}(\mathrm{O}) \\
& \mathrm{An}_{2} \mathrm{O}_{3}+\mathrm{Me} \leftrightarrow 2 \mathrm{AnO}+\mathrm{Me}(\mathrm{O}) \\
& \mathrm{AnO}(\mathrm{s})+\mathrm{Me} \leftrightarrow \mathrm{An}+\mathrm{Me}(\mathrm{O}) \\
& \mathrm{AnO}(\mathrm{g})+\mathrm{Me}(\mathrm{g}) \leftrightarrow \mathrm{An}(\mathrm{g})+\mathrm{Me}(\mathrm{O}) .
\end{aligned}
$$

Here, $\mathrm{Me}(\mathrm{O})$ refers to any thermodynamic sink for oxygen: oxide phases, solutions, or adsorbed states. In case of the isomolecular exchange reaction, Eq. (16), a large surplus of gaseous Me could shift the equilibrium in direction to the formation of gaseous An. The complementary product TiO introduces a dissociation enthalpy of $663 \mathrm{~kJ} / \mathrm{mol}$ [37]. A comparison with the dissociation enthalpies of the actinide monoxides in 


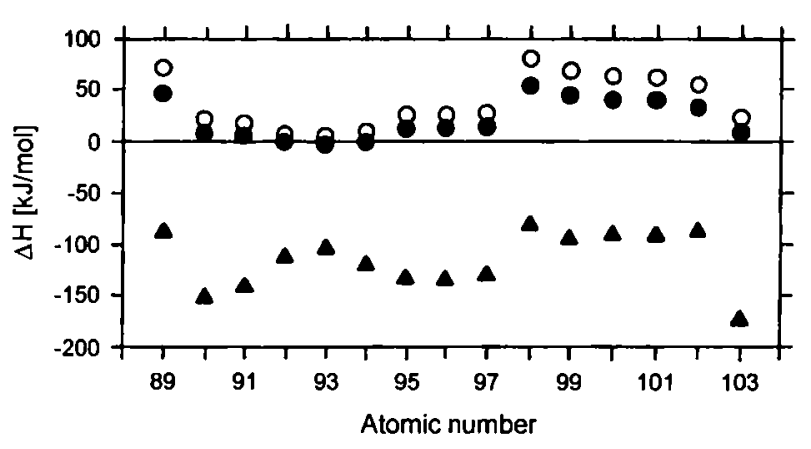

Fig. 3. Formation enthalpies of solid, ordered, equimolar intermetallic compounds of actinides with titanium (dots), tantalum (circles), and platinum (triangles), calculated [6] with the Miedema model [14].

Fig. 1, taking into account also the vapour pressure of titanium $[11,28]$, indicates that this reaction seems to be possible, at least for heavy actinides from einsteinium to nobelium. With tantalum, this reaction type is unlikely because of the low vapour pressure.

\section{Promotion and inhibition of actinide oxide reduction}

The equilibrium of reduction reactions can be shifted in different directions by side reactions. The volatilization of oxides $\mathrm{MeO}_{\mathrm{x}}$ fosters the volatilization of actinide particles An, the formation of complex oxides between An and $\mathrm{Me}$ inhibits it. When stable intermetallic compounds $\mathrm{An}_{\mathrm{x}} \mathrm{Me}_{\mathrm{y}}$ are formed, oxide reduction is favoured, but metal volatilization is hindered.

According to the vapour pressure data for titanium and tantalum and their oxides $[11,28]$ the gas phases contain only $\mathrm{Ti}, \mathrm{TiO}$, and $\mathrm{TiO}_{2}$, in dependence on the stoichiometry of the $\mathrm{TiO}_{x}$ system. At low oxygen concentrations, $\mathrm{Ti}$ and $\mathrm{TiO}$ are present, for $\mathrm{Ti}_{2} \mathrm{O}_{3}$ the monoxide TiO dominates, and for $\mathrm{Ti}_{5} \mathrm{O}_{9}$ it is $\mathrm{TiO}_{2}$ [42]. The situation in the $\mathrm{Ta}-\mathrm{O}$-system is analogous. From the thermodynamic data for oxygen solubility it follows, that titanium metal is able to extract oxygen from solid tantalum. In an open system (with a carrier gas or in vacuum), the volatilization of $\mathrm{TiO}$ from the reaction system should favour the reduction.

In order to discuss whether actinide metals are soluble in and react with titanium, tantalum, and platinum, Fig. 3 gives calculated formation enthalpies of solid, ordered, equimolar intermetallic compounds. They were calculated [6] on the basis of the Miedema model [14]. Formation enthalpies around zero indicate a high solubility in the solid state or mixed crystal formation, values below $+40 \mathrm{~kJ} / \mathrm{mol}$ point towards limited solubility, and values above $+40 \mathrm{~kJ} / \mathrm{mol}$ towards insolubility [43].

The results show that titanium and tantalum form no stable intermetallic compounds with actinides. Thus, an additional promotion of the reduction reaction is not expected, but a limited solubility of the actinides in these metals is likely. In general, the solubility of actinides in solid titanium should be higher than in tantalum. Very low solubilities in tantalum are expected for the divalent actinides from californium to nobelium.

With platinum, intermetallic compounds are formed, strongly favouring the reduction, but an additional reducing agent is needed (coupled reduction) because the ground reaction is not allowed thermodynamically. However, the compound formation strongly hinders the volatilization so that a thermal desorption from solid platinum can practically be excluded.

Experimental data on actinide solubilities in titanium are limited to thorium, uranium, and plutonium [37, 39], but with calcium and the lanthanides [44] as stand-in elements, the predicted trend in solubility: polyvalent $>$ trivalent $>$ divalent actinides is clearly observed [11], and also the higher solubility in titanium with respect to tantalum.

Data for the formation, structure, and stability of complex oxides are poor, especially thermochemical data. Well known is the formation of binary oxides with $\mathrm{TiO}_{\mathrm{x}}$ and $\mathrm{Ta}_{\mathrm{x}} \mathrm{O}_{\mathrm{y}}$. Their stability should increase with the basicity of the actinide oxides. In particular with trivalent metals such as $\mathrm{Lu}, \mathrm{Sc}, \mathrm{Ga}, \mathrm{In}, \mathrm{Al}$, and $\mathrm{Cr}$, complex oxides of the type $\mathrm{MeTiTaO}_{6}$ are formed [37], which should also exist for trivalent actinides. Reactions of actinide oxides with oxide coatings of the source materials hinder thermodynamically the reduction reactions because of the stabilization of the oxide phases, and they constitute also a diffusion barrier in the access to the free metal surface, thus deleting kinetically the reduction reaction.

Since the relevant processes occur under strongly reducing conditions, the behaviour of actinide oxides in lower oxidation states such as the +2 states are of particular interest. Hence, we focus on ternary oxides of the type $\mathrm{MeTiO}_{3}$ and estimate the stability of this type of compounds with monoxides of actinides by a comparison with the formation enthalpies of isotypic ternary oxides.

In order to identify the most likely lattice type, from the $\mathrm{An}^{2+}$ radii $R[45,46]$ the Goldschmidt factor $t_{\mathrm{G}}$ for the perovskite structure is calculated:

$$
t_{\mathrm{G}}=\frac{1}{\sqrt{2}} \cdot \frac{\left(\mathrm{R}_{\mathrm{Me}^{2+}}+\mathrm{R}_{\mathrm{O}^{2-}}\right)}{\left(\mathrm{R}_{\mathrm{Ti}^{4+}}+\mathrm{R}_{\mathrm{O}^{2-}}\right)}
$$

By comparing these calculated values for actinide elements with $t_{\mathrm{G}}$-values for compounds with known structure and formation enthalpies, one can estimate the structure and formation enthalpies of the actinide compounds [11]. According to Goldschmidt's criterion, perovskite structures are formed for $1>t_{\mathrm{G}}>0.91$. However, this structural type is also found with increasing deformation for calcium and cadmium with $t_{\mathrm{G}-\mathrm{Ca}}=0.868$ and $t_{\mathrm{G}-\mathrm{Cd}}=0.857$. For the actinides, $t_{\mathrm{G}}$ decreases from 0.980 at actinium to 0.875 at fermium; hence, the perovskite structure $\mathrm{MeTiO}_{3}$ seems to be very likely. However, for mendelevium and nobelium, with $t_{\mathrm{G}-\mathrm{Md}}=0.868$ and $t_{\mathrm{G}-\mathrm{No}}=0.864$, either deformed perovskite or ilmenite structures should be expected. 
Between the formation enthalpies $\Delta H_{\mathrm{f}}$ of perovskites of the alkaline earth elements calcium, strontium, and barium and their Goldschmidt factor $t_{\mathrm{G}}$, an empirical correlation exists [37]:

$$
\Delta H_{\mathrm{f}}[\mathrm{kJ} / \mathrm{mol}]=-677.96 \cdot t_{\mathrm{G}}+506.57
$$

and for ilmenites

$$
\Delta H_{\mathrm{f}}[\mathrm{kJ} / \mathrm{mol}]=-58.79 \cdot t_{\mathrm{G}}+21.31 .
$$

Using these correlations, the formation enthalpies $\Delta H_{\mathrm{f}}$ of the actinide compounds were estimated [11]. They decrease systematically from $-158 \mathrm{~kJ} / \mathrm{mol}$ for actinium to $-96 \mathrm{~kJ} / \mathrm{mol}$ for fermium and $-79 \mathrm{~kJ} / \mathrm{mol}$ for nobelium. For an ilmenite structure of the mendelevium and nobelium compounds, the stability should even be lower, as follows from an estimated $\Delta H_{\mathrm{f}}$ of $-30 \mathrm{~kJ} / \mathrm{mol}$. The relatively high formation enthalpies of the perovskites could lead to a strong hindrance of the reduction reactions, if the monoxides of the actinide elements would find unchanged $\mathrm{TiO}_{2}$ at the surface. This is rather unlikely, however, because of the high-temperature properties of the system $\mathrm{Ti}-\mathrm{TiO}_{2}$. In addition, one should expect that with increasing atomic number of the actinide elements, a possible hindrance of the reduction reaction by the formation of ternary $\mathrm{MeTiO}_{3}$ oxides plays a minor role.

\subsubsection{Diffusion of actinides in titanium and tantalum}

As a measure for the diffusion rate in the metals we consider the volume diffusion coefficient. This yields lower limits since we neglect grain-boundary diffusion which is much faster due to a considerably lower activation energy.

For the diffusion of actinides in $\beta$-titanium, only data for $\mathrm{U}$ [37] and $\mathrm{Pu}$ [44] are available, but the magnitude and temperature dependence is quite similar [11] as for comparable systems, Sc [37] and $\mathrm{Ta}$ [47] in titanium, and $\mathrm{Y}$ [48] and $\mathrm{Ce}$ [49] in zirconium. At $1200 \mathrm{~K}$, the diffusion coefficients $D$ are around $10^{-9}$ $\mathrm{cm}^{2} / \mathrm{s}$ [11]. For oxygen in titanium, the diffusion coefficient is much larger, $D \approx 10^{-7} \mathrm{~cm}^{2} / \mathrm{s}$ at $1200 \mathrm{~K}$ [37]. For diffusion in tantalum, more actinide data are known, namely for U, Pu, Cm [50], Cf, Es, Fm [51], Md [52], and for oxygen [53]. They are of the same order of magnitude [11], e.g. $D \approx 10^{-12} \mathrm{~cm}^{2} / \mathrm{s}$ at $1200 \mathrm{~K}$, whereas for oxygen, $D$ is again at the level of $\approx 10^{-7} \mathrm{~cm}^{2} / \mathrm{s}$ [53]. The fast oxygen diffusion in titanium and tantalum is of advantage for the reduction reaction, and should support the release of oxygen from the reaction in an open system. Diffusion of metals in titanium is much faster than in tantalum. Titanium belongs to the "anomalously fast diffusers" [54] whose diffusion coefficients for dissolved substances are by several orders of magnitude larger than for self-diffusion. The activation energies for dissolved substances are typically 0.3 to 0.5 times the self-diffusion energies.

Diffusion coefficients of $10^{-12} \mathrm{~cm}^{2} / \mathrm{s}$ as required for fast release of actinides from thin layers are
Table 2. Ionization potential $I_{\mathrm{i}}$ and electron work function $\Phi$ for

\begin{tabular}{|c|c|c|c|}
\hline $\begin{array}{l}\text { Metal } \\
\text { Me }\end{array}$ & $\underset{[\mathrm{eV}]}{\stackrel{I_{i} \text { for }}{\rightarrow} \mathrm{Me}^{+}}$ & $\underset{[\mathrm{MeO}]}{\stackrel{I_{i} \text { for }}{\rightarrow} \mathrm{MeO}^{+}}$ & $\begin{array}{c}\Phi \\
{[\mathrm{eV}]}\end{array}$ \\
\hline $\begin{array}{l}\text { Ac } \\
\text { Th } \\
\mathrm{Pa} \\
\text { U } \\
\mathrm{Np} \\
\mathrm{Pu} \\
\mathrm{Am} \\
\mathrm{Cm} \\
\mathrm{Bk} \\
\mathrm{Cf} \\
\mathrm{Es} \\
\mathrm{Fm} \\
\mathrm{Md} \\
\mathrm{No}\end{array}$ & $\begin{array}{l}5.2 \\
6.307^{*} \\
6.0 \\
6.194^{* *} \\
6.266^{*} \\
6.026^{*} \\
5.974^{*} \\
5.991^{*} \\
6.198^{*} \\
6.282^{*} \\
6.45 \\
6.5 \\
6.6 \\
6.6\end{array}$ & 5.7 & \\
\hline $\begin{array}{l}\mathrm{Ti}_{2} \\
\mathrm{Ti} \\
\mathrm{Ta} \\
\mathrm{Pt}\end{array}$ & $\begin{array}{l}6.82 \\
7.89 \\
8.96\end{array}$ & $\begin{array}{l}6.3 \\
6.8 \\
6.0\end{array}$ & $\begin{array}{l}3.95 \\
4.12 \\
5.32\end{array}$ \\
\hline
\end{tabular}
actinide metals and source materials

* From [55, 56], rounded.

** From [57], rounded.

All other data, partly estimated, taken from compilations [5860].

reached in titanium already at temperatures of about $1000 \mathrm{~K}$. For tantalum, about $200-300 \mathrm{~K}$ higher temperatures are needed. Hence in contact with titanium, tantalum constitutes a diffusion barrier for actinides.

\subsubsection{Desorption of actinides from metal surfaces}

Desorption from the metal surface is a decisive step for the nature of the gaseous species released, since it determines the abundances of neutral particles and ions, $\mathrm{An}(\mathrm{g}), \mathrm{AnO}(\mathrm{g}), \mathrm{An}^{+}$, and $\mathrm{AnO}^{+}$.

\section{Desorption of ions}

For a given actinide element, i.e., a given ionization potential, the fraction emitted as ion depends on the electron work function of the surface and the temperature (Eq. (5)). In Table 2, relevant data are compiled. Titanium offers the best conditions for the emission of neutral particles, whereas with tantalum at higher temperatures strong interferences by surface ionization have to be expected, as experimentally observed with actinides and lanthanides [61]. Platinum in pure form cannot be applied.

\section{Desorption of neutral atoms}

In a first approximation, the desorption enthalpy (negative adsorption enthalpy) can be considered as the crucial parameter in desorption kinetics (see 2.1.2). In [5], partial molar adsorption enthalpies of actinides on metal surfaces at zero coverage were calculated. 


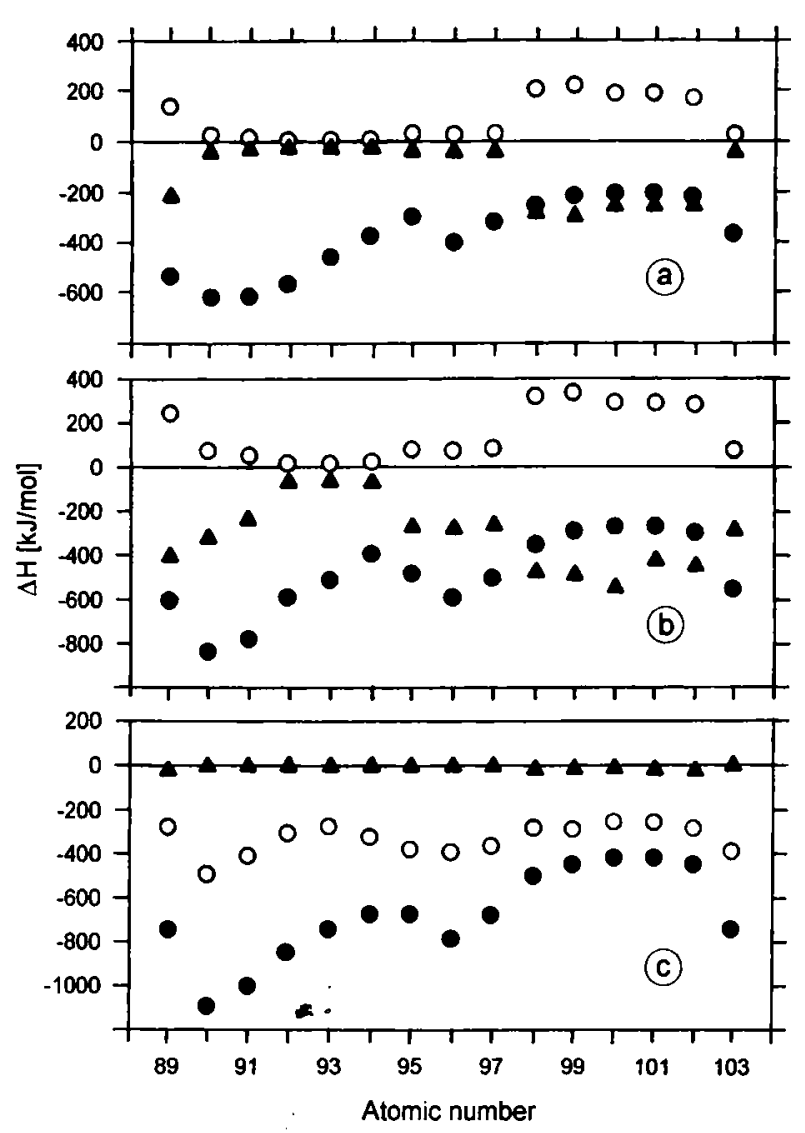

Fig. 4. Calculated enthhilpies of adsorption $\Delta H_{\text {ads }}$ (dots), solution $\Delta H_{\mathrm{SL}}$ (circles), and segregation $\Delta H_{\mathrm{SE}}$ (triangles) of actinide metals in interactions with (a) titanium, (b) tantalum, and (c) platinum [5].

Fig. 4 shows these adsorption enthalpies $\Delta H_{\text {ads }}$ on titanium, tantalum, and platinum, and also the solution enthalpies $\Delta H_{\mathrm{SL}}$ and segregation enthalpies $\Delta H_{\mathrm{SE}}$. Using Eq. (2), the desorption behaviour can be estimated.

Titanium (Fig. 4a) has very suitable properties for the desorption of actinides. Divalent actinides should be desorbed already below $1000 \mathrm{~K}$, plutonium and americium without problems slightly above $1000 \mathrm{~K}$. Only for thorium, protactinium, and uranium, temperatures around the melting point of titanium should be required. The solution enthalpies of actinides in titanium are somewhat less positive than in tantalum. Because of the considerably lower adsorption enthalpies of $\mathrm{Th}, \mathrm{Pa}, \mathrm{Am}, \mathrm{Cm}$, and $\mathrm{Lr}$ on titanium compared to tantalum, the driving force for their surface enrichment is smaller in titanium, but it remains still considerable even for divalent actinides.

From tantalum (Fig. 4b), any actinide element could be desorbed. For divalent actinides desorption should already occur at temperatures slightly above $1000 \mathrm{~K}$. For trivalent actinides, temperatures of about $2000 \mathrm{~K}$ are required, and for thorium and protactinium even much higher temperatures are needed. Under thermal stress, tantalum enriches the whole actinide group at the surface, as the $\Delta H_{\mathrm{SE}}$-values indicate. This

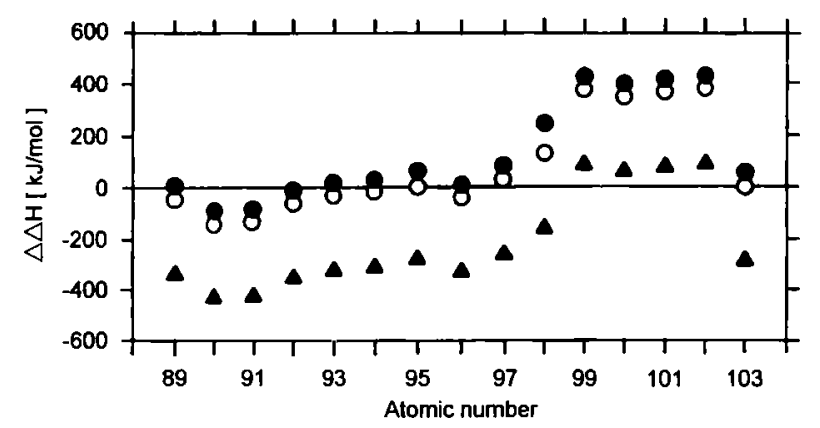

Fig. 5. Calculated differences between the enthalpies for associative desorption of actinides as monoxide, $\Delta H_{\text {des-Ano, }}$ and as metal, $\Delta H_{\text {des-An, }}$, from titanium (dots), tantalum (circles), and platinum surfaces (triangles).

is the key argument for using tantalum as the backing foil for actinide beam sources.

From platinum surfaces (Fig. 4c), desorption of actinide metals is nearly impossible before the melting point is reached. Because of the high solution enthalpies which correlate with the formation enthalpies of intermetallic compounds (Fig. 3), actinides are preferentially dissolved in the bulk phase. This is also evident from the low segregation enthalpies.

\section{Associative desorption}

In order to obtain an estimate for the probability of desorption of actinide monoxides, enthalpies for dissociative adsorption of the monoxides on metal surfaces were calculated [29]. This process can be considered as the reverse reaction of an associative desorption from surfaces. Fig. 5 shows the differences of the enthalpies for associative desorption as monoxide and as free atom from titanium, tantalum, and platinum surfaces. Associative desorption is favoured for negative values in this diagram.

These data take only into account contributions from surface material, actinide element and oxygen binding. In real systems the oxygen concentrations in the metal, on the surface and in the residual gas play a role, too. From titanium and tantalum, desorption as monoxide is likely for thorium and protactinium, and may also contribute for trivalent actinides. The divalent elements californium to nobelium should be desorbed as free atoms. The relatively high probability for monoxide desorption implies that the thermodynamic activity of oxygen in the total system should be kept as low as possible. Partial prevolatilization of oxygen, e.g. in the form of TiO, could be helpful. For platinum, monoxide desorption is very likely so that only for divalent actinides desorption of atoms may occur.

Experimental results on adsorption and desorption

Investigations of the desorption kinetics give access to binding energies between adsorbed atoms and surfaces. To a good approximation, the activation energy 
for desorption $E_{\text {des }}$ represents the negative adsorption enthalpy $\Delta H_{\text {ads }}$ which can be obtained, under certain conditions, with Eq. (2). Thermal desorption of actinides has not yet been studied systematically, but a few results and also data for several lanthanide elements are available.

The remarkably high volatility of americium, plutonium, and curium from surfaces of group IV $d$-metals and thorium was first reported in [62]. Actinium was completely volatilized from thorium beyond $1220 \mathrm{~K}$ [63]. The volatilization of americium from titanium and zirconium begins already at $1070 \mathrm{~K}$; and at $1470 \mathrm{~K}$ complete volatilization is achieved within $30 \mathrm{~min}[62,64]$. On the contrary, americium could not be volatilized from $\mathrm{W}, \mathrm{Ta}, \mathrm{Ni}$, steel, and $\mathrm{Pt}$ at temperatures up to $1470 \mathrm{~K}$. With platinum, diffusion into the bulk phase was observed. From experimentally determined activation energies for desorption from titanium surfaces, adsorption enthalpies $-\Delta H_{\text {ads }}=332 \mathrm{~kJ} / \mathrm{mol}$ were obtained for americium, and $334 \mathrm{~kJ} / \mathrm{mol}$ for curium [1]; this corresponds to temperatures of 1255 and $1245 \mathrm{~K}$, respectively, for $50 \%$ desorption within $1800 \mathrm{~s}$. Data [11] for the desorption of lanthanides from titanium [1] and tantalum $[65,66]$ may be useful for orientation.

In general, the kinetics of desorption processes depends strongly on the initial chemical state, the surface properties of the matrix metals and the composition of the surrounding gas atmosphere. The experimentally observed activation energies for desorption characterize, hence, the rate determining step in an often complex surface interaction. Nonetheless, desorption energies obtained in single-step experiments are useful as an orientation for practical applications. More insights into the interaction of trace amounts of chemically reactive elements with metallic surfaces are provided by multistep processes such as thermochromatography.

Thermochromatography is a variant of adsorption gas chromatography. In a stationary, negative temperature gradient, the species to be studied form internal chromatograms whose peak positions are determined by the strength of the particle-surface interaction and by the experimental conditions. With thermochromatographic methods, the adsorption of lanthanide elements on titanium was investigated $[1,2]$, and similar studies were carried out for the relatively volatile elements Am, Cf, Es, Fm, and Md [2-4, 67-70]. The observed deposition temperatures $T_{\text {ads }}$ and the adsorption enthalpies $\Delta H_{\text {ads }}$ deduced from such data according to the prescription of Ref. [71] are compiled in Table 3. Further data on lanthanide elements are given elsewhere [11].

In Fig. 6, the adsorption enthalpies derived from experimental studies of thermal desorption and thermochromatography are compared to calculated values $[5,72]$. On the whole, the calculations predict quite well the desorption behaviour of actinides from metal surfaces.
Table 3. Thermochromatography of actinides in titanium and zirconium columns

\begin{tabular}{ccccc}
\hline $\begin{array}{c}\text { Ele- } \\
\text { ment }\end{array}$ & $\begin{array}{c}\text { Adsor- } \\
\text { bens }\end{array}$ & $\begin{array}{c}\text { Deposition } \\
\text { temperature } \\
T_{\text {ads }}[\mathrm{K}]\end{array}$ & $\begin{array}{c}\text { Adsorption } \\
\text { enthalpy } \\
-\Delta H_{\text {ads }} \\
{[\mathrm{kJ} / \mathrm{mol}]}\end{array}$ & $\begin{array}{c}\text { Refer- } \\
\text { ence }\end{array}$ \\
\hline $\mathrm{Am}$ & $\mathrm{Ti}$ & 970 & 285 & {$[67]$} \\
$\mathrm{Cf}$ & $\mathrm{Ti}$ & 930 & 268 & {$[68]$} \\
& & 775 & 176 & {$[3]$} \\
& & 810 & 201 & {$[70]$} \\
$\mathrm{Es}$ & $\mathrm{Ti}$ & 720 & 163 & {$[3]$} \\
& & 930 & 220 & {$[4]$} \\
& & 760 & 189 & {$[70]$} \\
$\mathrm{Fm}$ & $\mathrm{Ti}$ & 720 & 163 & {$[3]$} \\
& & 890 & 210 & {$[4]$} \\
& & 730 & 182 & {$[70]$} \\
& $\mathrm{Zr}$ & 870 & 222 & {$[68]$} \\
$\mathrm{Md}$ & $\mathrm{Ti}$ & 930 & 239 & {$[68]$} \\
& $\mathrm{Zr}$ & 870 & 162 & {$[3]$} \\
& & 930 & 222 & {$[68]$} \\
& & & 239 & {$[68]$} \\
\hline
\end{tabular}

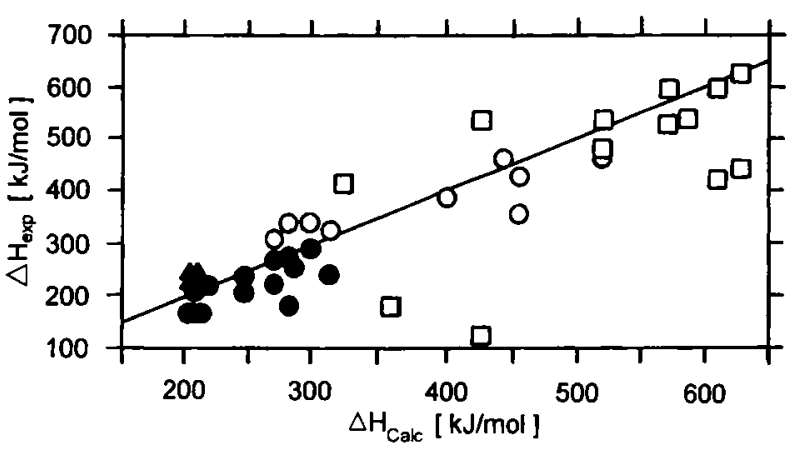

Fig. 6. Comparison of experimental and calculated adsorption enthalpies of actinide and lanthanide metals on titanium (circles), zirconium (triangles), and tantalum surfaces (squares); experimental data obtained by thermochromatography (filled) and thermodesorption (empty symbols).

\subsubsection{Phase stability and compatibility of metallic titanium and tantalum}

Metallic titanium and tantalum are completely miscible at high temperatures i.e. $\beta$-Ti and Ta form a complete series of solid solutions whereas in $\alpha$-Ti, the solubility of $\mathrm{Ta}$ is limited. The stability range of the phases are for titanium <1155 K $\alpha$-Ti (hcp); $1155-1933 \mathrm{~K}$ $\beta$-Ti (bcc); and for tantalum $<3269 \mathrm{~K} \mathrm{Ta}$ (bcc). At high temperatures, a mixing of the components could occur. The lowest melting point in the system is that of titanium.

\section{Atomic beam source}

\subsection{Concept}

From the thermodynamic and kinetic data presented in the preceding sections it follows that straightforward evaporation from any metal surface is not a promising approach to develop an efficient atomic beam source for actinide elements. Rather, a sandwich-type source 
is required: the actinide element in oxidic form is deposited on a mechanically and thermally stable substrate foil and covered with a thin metallic coating of high reductive power.

Tantalum is the best choice for the substrate foil. In addition to its mechanical stability even at high temperatures, tantalum has the very favourable property to enrich actinides at the foil surface and to form a diffusion barrier against back diffusion into the substrate.

Titanium is the choice for the surface coating because of its high reductive potential and low electron work function, and because of the low adsorption enthalpy and high diffusion rate for actinides in this metal. Titanium is applied as a thin, dense metallic layer.

In such a sandwich source, three time-consuming, thermally activated processes - reduction, diffusion, and desorption - occur which should lead, at suitable operation temperatures, to a relatively slow, steady release of actinide atoms and, finally, nearly complete volatilization of the actinide sample.

\subsection{Preparation of tantalum-actinide oxide-titanium sandwich filaments}

The actinide elements are electrochemically deposited $[73,74]$ on tantalum backings as actinide hydroxides in form of a spot of $3 \mathrm{~mm}$ diameter. An $11 \times 3.5 \mathrm{~mm}$ tantalum foil, $50 \mu \mathrm{m}$ thick, is operated as the cathode in the electrolytic cell, a platinum wire is the anode. The electrolyte is a $1.5 \mathrm{M}$ ammonium sulfate solution of $\mathrm{pH}$-value 1.5 to 2.0 , the current density is about $3.5 \mathrm{~A} / \mathrm{cm}^{2}$, and the time of deposition about $60 \mathrm{~min}$. Yields are between 60 to 80 per cent. After drying, the hydroxide-on-tantalum filament is covered with an about $1 \mu \mathrm{m}$ thick titanium layer. Evaporation-condensation of titanium in high vacuum as well as sputtering were applied as coating procedures, with much better results obtained for sputtering. Uniformity and thickness are checked by $\alpha$-particle spectroscopy with surface barrier detectors. For a uniform titanium coating a sharp $\alpha$-energy peak is observed which is shifted to somewhat lower energies due to the absorption of $\alpha$ particles in the titanium layer. From this shift the thickness of the coating can be deduced [73]; e.g., for a $0.9 \mu \mathrm{m}$ thick titanium coating a shift of $0.20 \mathrm{MeV}$ of the $5.148 \mathrm{MeV} \alpha$-particles of ${ }^{239} \mathrm{Pu}$ results. When the coating is less uniform or has holes, broader and structured energy distributions are obtained.

\subsection{Experimental tests of the sandwich sources}

Experimental tests of the sandwich actinide beam sources were performed by RIMS using the setup described in Ref. [8]. Atomic beams are produced by heating the sandwich filament. They are then ionized by three intersecting laser beams of different wavelength in a sequence of three resonant excitation-

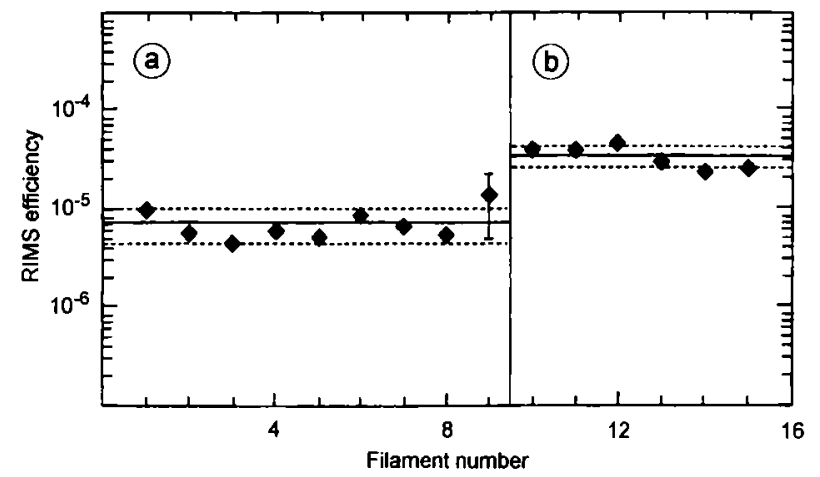

Fig. 7. Overall efficiency for the detection of plutonium with RIMS using atomic beams from tantalum-plutonium oxidetitanium sandwich filaments; titanium coatings applied by (a) evaporation, (b) sputtering; source temperature $1270 \mathrm{~K}$.

ionization steps. The ions are accelerated in an electric field and analyzed in a time-of-flight mass spectrometer. They are finally counted by a channelplate detector located at the end of the RIMS setup. The laser beams are delivered by three tunable dye lasers, pumped simultaneously by two copper vapour lasers. The high repetition rate of $6.5 \mathrm{kHz}$ provides a good temporal overlap with the continuously produced atomic beam, as is required for achieving high detection sensitivity.

For applications in ultratrace analysis, high efficiency and good reproducibility of the atomic beam production is a prerequisite, for studies of atomic properties the controlled, steady release over long periods is a necessity.

\subsubsection{Reproducibility}

The reproducibility was checked by measuring the overall efficiency of RIMS with a series of filaments carrying the same actinide amount. This efficiency is defined as the number of ions counted with the RIMS detector, compared to the number of atoms originally present on the filament. The source strength is determined by $\alpha$-particle spectroscopy. The RIMS efficiency includes any loss of actinide material between source and detector. With a well tuned RIMS setup, apparative factors should be rather constant. Hence, fluctuations in the overall efficiency from sample to sample reflect largely the reproducibility of the atomic beam source.

Fig. 7 shows results of tests with a series of filaments containing the same quantity of ${ }^{239} \mathrm{Pu}$, $10^{11}$ atoms. Titanium coatings were deposited by evaporation or sputtering. The sources were run for 2 to $4 \mathrm{~h}$ at $1270 \mathrm{~K}$. With sputtered coatings, the overall efficiency and reproducibility are superior compared to evaporated coatings, as shown by the respective averages of $3.4( \pm 0.8) \cdot 10^{-5}$ compared to $7.4( \pm 2.8)$ $\cdot 10^{-6}$. Obviously, sputtering yields more uniform coatings. The evaporation of plutonium under such conditions is nearly complete, with only a few percent 


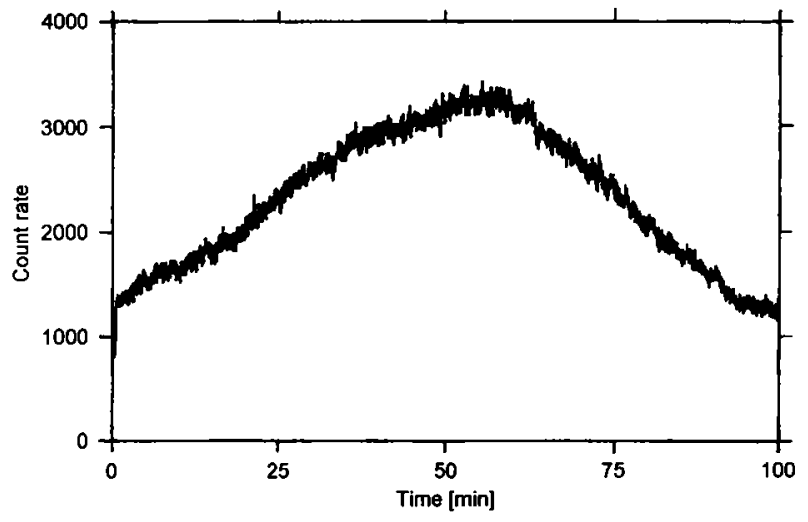

Fig. 8. Time profile of the RIMS count rate for curium released from a tantalum-curium oxide-titanium sandwich source operated at $1410 \mathrm{~K}$.

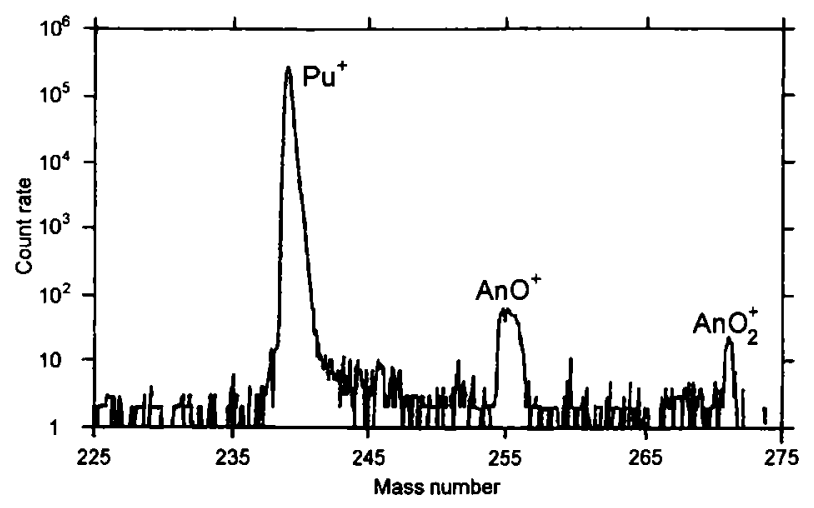

Fig. 9. Oxidic contaminants in a plutonium beam released at $1270 \mathrm{~K}$ from a tantalum-plutonium oxide-titanium sandwich source as revealed by the RIMS mass spectrum.

remaining on the filaments, as is found by $\alpha$-particle spectroscopy after use.

\subsubsection{Time profile of volatilization}

A time profile of the volatilization from a tantalumactinide oxide-titanium sandwich is shown in Fig. 8 for a sample of $10^{11}$ atoms of ${ }^{248} \mathrm{Cm}$ run at $1410 \mathrm{~K}$. The shape of the curve indicates different rate-determining processes. The initial increase is due to the transport of curium metal to the surface, determined by the thermally activated processes of reduction and diffusion. The subsequent descent is caused by the increasing depletion of the source between the tantalum and titanium layers and at the titanium surface. Such a time profile is well suited for spectroscopic investigations whereas with the previously applied, rhenium-based filaments the temperature had to be increased stepwise to achieve good yields [73].

\subsubsection{Evaporation of neutral molecules}

Since actinide oxides are formed during heating the source, the formation of neutral monoxide and dioxide molecules due to incomplete reduction to the metal has to be proven and kept at a minimum. Fig. 9 depicts a time-of-flight mass spectrum of a ${ }^{239} \mathrm{Pu}$ sample obtained by RIMS. In addition to the plutonium signal at mass number 239, small peaks around mass numbers 255 and 270 can be seen which could be assigned to the molecular ions $\mathrm{PuO}^{+}$and $\mathrm{PuO}_{2}^{+}$, non-resonantly ionized by the laser light. However, since the sample should contain a surplus of uranium from contaminants, ${ }^{238} \mathrm{UO}^{+}$and ${ }^{238} \mathrm{UO}_{2}^{2+}$ from non-resonant processes may also contribute. In any case, the intensities are orders of magnitude smaller than that of the $\mathrm{Pu}^{+}$ signal.

\section{Operating experiences and some applications}

Sandwich sources were so far used for RIMS measurements of plutonium, curium, berkelium, and californium. In Table 4 operation conditions and some characteristic properties are summarized. The overall RIMS efficiency is mainly determined by the limited spatial and temporal overlap between the continuous atomic beam and the pulsed laser beams. For plutonium the measured efficiency of $3 \cdot 10^{-5}$ (Table 4) can be compared with a calculated value of $2 \cdot 10^{-4}$ [75] obtained with reasonable assumptions for all individual factors contributing, but assuming $100 \%$ source efficiency. This results in a source efficiency of 10 to $20 \%$ which should be a lower limit since in practice some assumptions made are not always reached, e.g., the photon intensities are not sufficient to saturate all excitation steps.

The low operation temperatures are an important advantage, being most pronounced - as expected for berkelium and californium. Consequently, the spectra are nearly free from background events, and very low detection limits can thus be achieved. The limits are estimated from the statistical $3 \sigma$ limit of the number of background events accumulated during a typical operation time. The detection limits listed in Table 4 correspond to a few femtograms of the actinide elements.

The superior sensitivity of RIMS is demonstrated by Fig. 10 where the same ${ }^{239} \mathrm{Pu}$ sample was analyzed for plutonium by conventional $\alpha$-particle spectroscopy and by RIMS. Whereas with $\alpha$-particle spectroscopy a counting time of $23.5 \mathrm{~h}$ is required to obtain a statistically significant signal, RIMS yields within $1.5 \mathrm{~h}$ a signal stronger by three orders of magnitude.

As an application to environmental analysis, RIMS measurements of two plutonium samples are depicted in Fig. 11. One sample was chemically isolated from a hot particle from the Chernobyl area. An activity of $45 \mathrm{mBq}{ }^{239,240} \mathrm{Pu}$ was measured by $\alpha$-particle spectroscopy which cannot resolve the nearly identical $\alpha$ lines of these two isotopes. In the RIMS spectrum, Fig. 11a, these two isotopes are clearly resolved. Also seen is ${ }^{241} \mathrm{Pu}$, a pure $\beta$-ray emitter which escapes $\alpha$ particle counting, and two minor components, the $\alpha$-emitters ${ }^{238} \mathrm{Pu}$ with $0.9 \%$, and ${ }^{242} \mathrm{Pu}$ with $1.2 \%$ abundance. A known activity of a tracer, the $\alpha$-emitter 
Table 4. RIMS studies with atomic beams produced by tantalum-actinide oxide-titanium sandwich sources

\begin{tabular}{lcccc}
\hline Parameter & Plutonium & Curium & Berkelium & Californium \\
\hline Source temperature [K] & 1270 & 1390 & 1020 & 1020 \\
Overall RIMS efficiency & $3 \cdot 10^{-5}$ & $6.5 \cdot 10^{-6}$ & $1 \cdot 10^{-5}$ & $*$ \\
Detection limit & $1 \cdot 10^{6}$ & $7 \cdot 10^{6}$ & $6 \cdot 10^{6}$ & $*$ \\
$\quad$ number of atoms & 0.4 & 3 & 2 & $*$ \\
femtogram & small & small & neglibile & negligible \\
\hline
\end{tabular}

* Not yet determined.

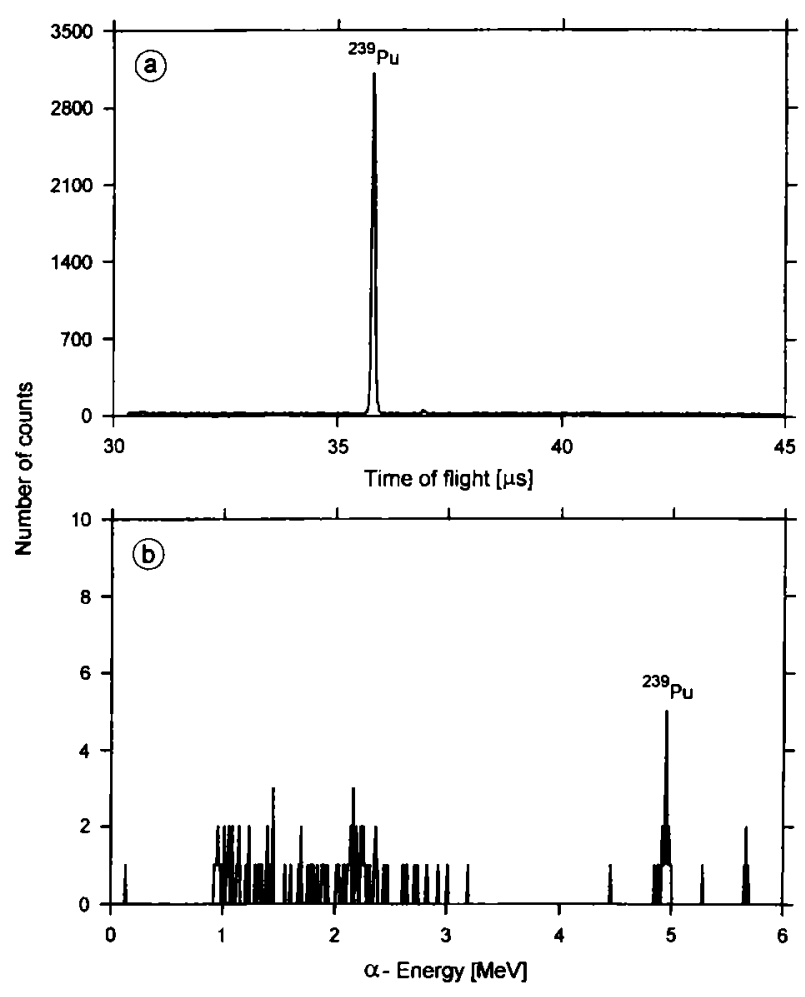

Fig. 10. Comparison of RIMS and $\alpha$-particle spectroscopy in the detection of $10^{9}$ atoms ${ }^{239} \mathrm{Pu}(=0.4 \mathrm{pg}=1 \mathrm{mBq})$ : (a) RIMS time-of-flight spectrum accumulated during $1.5 \mathrm{~h}$ counting time, (b) $\alpha$-particle spectrum after $23.5 \mathrm{~h}$ counting time; energy shift due to a $1 \mu \mathrm{m}$ thick titanium covering layer.

${ }^{236} \mathrm{Pu}$, was added to determine chemical yield and RIMS efficiency. The isotopic distribution is typical for reactor plutonium, and the obtained isotope abundances are in good agreement with the operation data of the Chernobyl reactor.

The RIMS spectrum in Fig. 11b refers to a plutonium sample isolated from Pacific Ocean sediments at the Mururoa Atoll. Here, ${ }^{244} \mathrm{Pu}$ was added for efficiency monitoring. The spectrum is dominated by ${ }^{239} \mathrm{Pu}$ with little ${ }^{240} \mathrm{Pu}$, as is typical for weapon plutonium. The total plutonium activity measured in the sediment, $31 \mathrm{mBq} / \mathrm{g}$, is in agreement with the certificate of the International Atomic Energy Agency.

As an example for RIMS measurements of fundamental atomic properties, we refer to the first determination of the ionization potentials of americium, curium [55], berkelium, and californium [56]. Due to the high overall efficiency of the RIMS technique in-

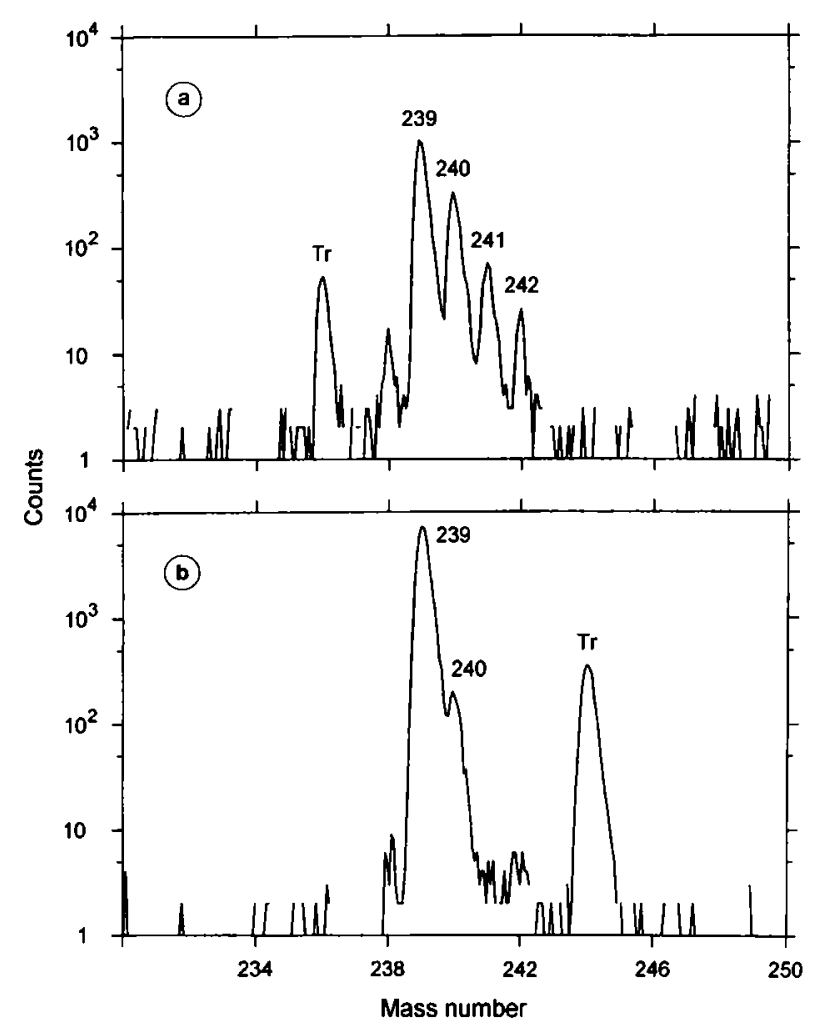

Fig. 11. RIMS mass spectra of the plutonium fraction separated from two environmental samples [76]: (a) a hot particle from the Chernobyl area, (b) a Pacific Ocean sediment from the Mururoa Atoll. "Tr" marks ${ }^{236} \mathrm{Pu}$ or ${ }^{244} \mathrm{Pu}$ tracers added for the determination of chemical yield and RIMS efficiency.

cluding atomic beam production, these measurements could be carried out with only $10^{12}$ atoms $(=0.4 \mathrm{ng})$ of the respective actinide elements.

In order to explore whether such sandwich-type atomic beam sources could be applied to actinide elements not yet studied experimentally, the operation temperatures for sandwich sources of the whole actinide series were estimated, assuming that desorption is rate-determining and the volatilization reaches a yield of $F=0.9$ during $t=1.5 \mathrm{~h}$. With the relation

$$
T_{v}=\frac{-\Delta H_{\mathrm{ads}}}{R\left(\ln \left(\frac{t}{(-\ln (1-F))}\right)+\ln v_{0}\right)}
$$

the operation temperatures given in Fig. 12 are obtained. The frequency $v_{0}$ is derived as: 


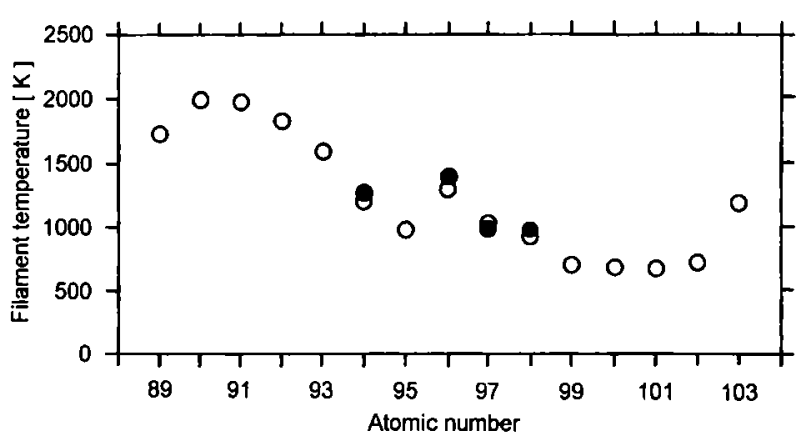

Fig. 12. Calculated operation temperatures for tantalum-actinide oxide-titanium atomic beam sources of the actinide elements (circles) and comparison with experimental data (dots).

$$
v_{0}=\frac{k \cdot \Theta}{h}=8.8736 \cdot 10^{12}\left[\mathrm{~s}^{-1}\right]
$$

from the Debye temperature, $\theta=426 \mathrm{~K}$, which is deduced from the specific heat of titanium [77]. For plutonium, curium, berkelium, and californium, the agreement with our experimental experiences is remarkable. For americium and for the elements einsteinium to lawrencium, a tantalum-actinide oxide-titanium sandwich source should function without problems. Thorium, protactinium, and uranium require filament temperatures close to the melting point of titanium. Under such conditions, titanium would most likely diffuse into the tantalum backing. Whether such filaments would work has to be proven experimentally. An alternative for these elements could be a tantalum-actinide oxide-zirconium sandwich. It should be noted, that due to the model conditions chosen, the calculated operation temperatures may be lower limits.

\section{Conclusions}

From experimental data and interpolations of thermodynamic and kinetic properties of actinide elements and possible source materials, a tantalum-actinide oxide-titanium sandwich source was developed for the production of atomic beams of actinide elements. The experimental verification of this approach in RIMS experiments with plutonium, curium, berkelium, and californium proves these sources to be efficient and stable with remarkably low operation temperatures. The sandwich composition should generally be applicable to the whole actinide series, except one or two of the lightest actinide elements.

\section{Acknowledgements}

We would like to thank Andrea Nähler and Stefanie Rauch for their collaboration in the development and application of electrochemical procedures. Two of us (B. E. and S. H.) gratefully acknowledge the hospitality of the Institut für Kernchemie, Universität Mainz. This work has been supported by the German Bundesministerium für Umwelt, Naturschutz und
Reaktorsicherheit, by the Bundesamt für Strahlenschutz, and by the Bundesministerium für Bildung, Wissenschaft, Forschung und Technologie.

\section{References}

1. Eichler, B., Frink, C., Herrmann, G., Trautmann, N.: Fresenius Z. Analyt. Chem. 335, 656 (1989).

2. Hübener, S., Zvara, I.: Radiochim. Acta 27, 157 (1980).

3. Hübener, S., Zvara, I.: Radiochim. Acta 31, 89 (1982).

4. Hübener, S., Eichler, B., Schädel, M., Brüchle, W., Gregorich, K. E., Hoffman, D. C.: J. Alloys Compounds 213/214, 429 (1994).

5. Eichler, B., Hübener, S., Rossbach, H.: Zentralinstitut für Kernforschung Rossendorf, Report ZfK-560 (1988).

6. Eichler, B., Rossbach, H.: Zentralinstitut für Kernforschung Rossendorf, Report ZfK-649 (1988).

7. Peuser, P., Herrmann, G., Rimke, H., Sattelberger, P., Trautmann, N., Ruster, W., Ames, F., Bonn, J., Kluge, H.-J., Krönert, U., Otten, E.-W.: Appl. Phys. B38, 249 (1985).

8. Ruster, W., Ames, F., Kluge, H.-J., Otten, E.-W., Rehklau, D., Scheerer, F., Herrmann, G., Mühleck, C., Riegel, J., Rimke, H., Sattelberger, P., Trautmann, N.: Nucl. Instr. Methods Phys. Res. A281, 547 (1989).

9. Riegel, J., Deißenberger, R., Herrmann, G., Köhler, S., Sattelberger, P., Trautmann, N., Wendeler, H., Ames, F., Kluge, H.-J., Scheerer, F., Urban, F.-J.: Appl. Phys. B56, 275 (1993).

10. Erdmann, N., Albus, F., Deißenberger, R., Eberhardt, K., Funk, H., Hasse, H.-U., Herrmann, G., Huber, G., Kluge, H.-J., Köhler, S., Nunnemann, M., Passler, G., Trautmann, N., Urban, F.-J.: In Resonance Ionization Spectroscopy 1994 (H.-J. Kluge, J. E. Parks, K. Wendt, eds.), AIP Conf. Proc. Vol. 329, p. 507. Amer. Inst. Physics, New York 1995.

11. Eichler, B., Hübener, S., Erdmann, N., Eberhardt, K., Funk, H., Herrmann, G., Köhler, S., Trautmann, N., Passler, G., Urban, F.-J.: Paul Scherrer Institut Villigen Report 96-03 (1996).

12. De Boer, M.: In Molecular Processes on Solid Surfaces (E. Drauglitz, R. D. Gretz, R. J. Jaffee, eds.), p. 3. Graw-Hill, New York 1968.

13. Crank, J.: Mathematics of Diffusion, Oxford Univ. Press. 1975.

14. Miedema, A. R.: Faraday Symp. Chem. Soc. 14/15, 136 (1980).

15. Gingerich, K. A.: Faraday Symp. Chem. Soc. 14/15, 109 (1980).

16. Kleinschmidt, P. D., Ward, J. W.: J. Less-Common Met. 121, 61 (1986).

17. Phipps, T. E., Sears, G. W., Simpson, O. C.: J. Chem. Phys. 18, 724 (1950).

18. Ackermann, R. J., Faircloth, R. L., Rand, M. H.: J. Phys. Chem. 70, 3698 1966).

19. Smith, P. K., Peterson, D. E.: J. Chem. Phys. 52, 4963 (1970).

20. Haire, R. G.: J. Alloys Compounds 213/214, 185 (1994).

21. Ackermann, R. J., Chandrasekharaiah, M. S.: In Thermodynamics of Nuclear Materials 1974, Vol. 2, p. 3. Int. Atomic Energy Agency, Vienna 1975.

22. Ackermann, R. J., Rauh, E. G., Thorn, R. J., Cannon, M. C.: J. Phys. Chem. 67, 762 (1963).

23. Benezech, G., Coutures, J. P., Foex, M.: In Thermodynamics of Nuclear Materials 1974, Vol. 2, p. 337. Int. Atomic Energy Agency, Vienna 1975.

24. Ackermann, R. J., Faircloth, R. L., Rauh, E. G., Thorn, R. J.: J. Inorg. Nucl. Chem. 28, 111 (1966).

25. Ackermann, R. J., Thorn, R. J.: In Thermodynamics of $\mathrm{Nu}$ clear Materials 1962, p. 445. Int. Atomic Energy Agency, Vienna 1962.

26. Donovan, J. A., Rankin, D. J., Stuckey, J. R., McDonell, W. R.: Trans. Am. Nucl. Soc. 13, 83 (1979). 
27. Morss, L. R., Fuger, J., Goffart, J., Edelstein, N., Shalimov, G. V.: J. Less-Common Met. 127, 251 (1987).

28. Knacke, O., Kubaschewski, O., Hesselmann, K.: Thermochemical Properties of Inorganic Substances. Springer, Heidelberg 1991.

29. Eichler, B., Hübener, S., Rossbach, H.: Zentralinstitut für Kernforschung Rossendorf, Report ZfK-609 (1986).

30. Morss, L. R.: In The Chemistry of the Actinide Elements, (J. J. Katz, G. T. Seaborg, L. R. Morss, eds.), Vol. 2, p. 1292. Chapman and Hall, New York 1986.

31. Ward, J. W., Kleinschmidt, P. D., Peterson, D. E.: In Handbook on the Physics and Chemistry of the Actinides (A. J. Freeman, C. Keller, eds.), Vol. 4, p. 309. Elsevier, Amsterdam 1986.

32. Haire, R. G., Gibson, J. K.: J. Chem. Phys. 91, 7085 (1989).

33. Fast, J. D.: Interaction of Metals and Gases, Vol. 1: Thermodynamics and Phase Relations. Centrex Publ., Eindhoven 1965

34. Kubaschewski, O.: Praktische Anwendungen der metallischen Thermodynamik, Rheinisch-Westfälische Akad. Wiss., Vorträge No. 232, p. 16. Westdeutscher Verlag, Opladen 1973.

35. Quach-Kamimura, T. H., David, D., Beranger, G., Falanga, A., Lozes, G.: J. Less-Common Met. 125, 59 (1986).

36. Tetot, R., Picard, C., Boureau, G., Gerdanian, P.: J. Chem. Phys. 69, 326 (1978).

37. Kubaschewski, O.: In Titanium - Physico-chemical Properties of its Compounds and Alloys, Spec. Iss. No. 9 (K. L. Komarek, ed.), p. 441. Int. Atomic Energy Agency, Vienna 1983.

38. Fromm, E., Kirchheim, R.: Z. Metallkunde 66, 144 (1975).

39. Von Goldbeck, O., Livey, D. T.: In Tantalum - Physicochemical Properties of its Compounds and Alloys, Spec. Iss. No. 3 (O. Kubaschewski, ed.), p. 41. Int. Atomic Energy Agency, Vienna 1972.

40. Boureau, G., Gerdanian, P.: J. Phys. Chem. Solids 42, 749 (1981).

41. Komarek, K. L., Silver, M.: Thermodynamics of Nuclear Materials 1962, p. 749. Int. Atomic Energy Agency, Vienna 1962.

42. Gilles, P. W., Conrad, B. R., Sheldon, R. I., Bennett, J. E.: In Thermodynamics of Nuclear Materials 1974, Vol. 2, p. 499. Int. Atomic Energy Agency, Vienna 1975.

43. De Boer, F. R., Boom, R., Miedema, A. R.: Physica 101B, 294 (1980).

44. Languille, A.: Mem. Sci. Rev. Met. 68, 435 (1971).

45. Morss, L. R.: In Ref. [30], p. 1284.

46. Morss, L. R.: J. Less-Common Met. 93, 301 (1983).

47. Hood, G. M.: J. Phys. F 6, 19 (1976).

48. Beyer, G.-J., Novgorodov, A. F., Kovalev, A. S.: Isotopenpraxis 18, 23 (1981).

49. Paul, A. R., Agarwala, R. P.: Thermodynamics of Nuclear Materials 1974, Vol. 1, p. 109. Int. Atomic Energy Agency, Vienna 1975.

50. Legoux, Y., Merini, J.: J. Less-Common Met. 144, 165 (1988).

51. Legoux, Y., Merini, J.: J. Less-Common Met. 121, 49 (1986).

52. Legoux, Y., Merini, J.: J. Less-Common Met. 160, 363 (1990).
53. Dragoo, A. L.: In Tantalum - Physico-chemical Properties of its Compounds and Alloys, Spec. Iss. No. 3 (O. Kubaschewski, ed.), p. 131. Int. Atomic Energy Agency, Vienna 1972.

54. Le Claire, A. D.: J. Nucl. Mater. 69/70, 76 (1978).

55. Deissenberger, R., Köhler, S., Ames, F., Eberhardt, K., Erdmann, N., Funk, H., Herrmann, G., Kluge, H.-J., Nunnemann, M., Passler, G., Riegel, J., Scheerer, F., Trautmann, N., Urban, F.-J.: Angew. Chem. 107, 891 (1995); Angew. Chem. Int. Ed. Engl. 34, 814 (1995).

56. Köhler, S., Erdmann, N., Nunnemann, M., Herrmann, G., Huber, G., Kratz, J. V., Passler, G., Trautmann, N.: Angew. Chem. 108, 3036 (1996); Angew. Chem. Int. Ed. Engl. 35, 2856 (1996).

57. Coste, A., Avril, R., Blancard, P., Chatelet, J., Lambert, D., Legre, J., Liberman, S., Pinard, J.: J. Opt. Soc. Am. 72, 193 (1982).

58. Radzig, A. A., Smirnov, B. M.: Spravocnik po atomnoi $i$ molekularnoi fizike. Atomizdat, Moskva 1980.

59. Fomenko, V. S., Podcemjaeva, F. A.: Emissionnye $i$ adsorpzionnye svoistva vescestv $i$ materialov. Atomizdat, Moskva 1975.

60. Gurvic, L. B.: Energija razriva Khimiceskikh svajzei. Izd. Nauke, Moskva 1974.

61. Beyer, G. J., Herrmann, E., Piotrowski, A., Raiko, V. J., Tyrroff, H.: Nucl. Instr. Methods 96, 437 (1971).

62. Reetz, T.: Dissertation B, Technische Universität Dresden 1977.

63. Reetz, T., Eichler, B.: Kernenergie 18, 162 (1975).

64. Zhuikov, B. L., Reetz, T., Zvara, I.: Radiokhimiya 28, 246 (1986); Sov. J. Radiochem. 28, 221 (1986).

65. Beyer, G.-J., Novgorodov, A. F.: Zentralinstitut für Kernforschung Rossendorf, Report ZfK-305 (1976).

66. Medvedev, B. K.: Fiz. Tverd. Tela (Leningrad) 16, 1903 (1974).

67. Eichler, B., Rhede, E.: Kernenergie 23, 191 (1980).

68. Eichler, B., Buklanov, G. V., Timokhin, S. N.: Kernenergie 30, 469 (1987).

69. Fremont-Lamouranne, R., Legoux, Y., Merini, J., Zhuikov, B. L., Eichler, B.: In Handbook of the Physics and Chemistry of the Actinides (A. J. Freeman, C. Keller, eds.), Vol. 3, p. 331. Elsevier, Amsterdam 1986.

70. Taut, S., Hübener, S., Eichler, B., Gäggeler, H. W., Schädel, M., Zvara, I.: Radiochim. Acta 78, 33-38 (1997).

71. Eichler, B., Zvara, I.: Radiochim. Acta 30, 233 (1982).

72. Eichler, B., Hübener, S., Rossbach, H.: Zentralinstitut für Kernforschung Rossendorf, Report ZfK-561 (1989).

73. Wendeler, H., Deissenberger, R., Urban, F.-J., Trautmann, N., Herrmann, G.: Nucl. Instr. Methods Phys. Ref. A334, 93 (1993).

74. Eberhardt, K., Erdmann, N., Funk, H., Herrmann, G., Köhler, S., Nähler, A., Passler, G., Trautmann, N., Urban, F.-J.: In Ref. [10], p. 507.

75. Urban, F.-J.: Doctoral Dissertation, Universität Mainz 1994.

76. Erdmann, N., Herrmann, G., Huber, G., Köhler, S., Kratz, J. V., Mansel, A., Nunnemann, M., Passler, G., Trautmann, N., Waldek, A.: Proc. 8th Int. Symp. Resonance Ionization Spectroscopy and its Applications, Pittsburgh 1996, AIP Conf. Proc., Amer. Inst. Physics, New York, in press.

77. Gscheidner, K. A.: Solid State Phys. 16, 275 (1964). 
